\title{
SERVIÇO SOCIAL E SAÚDE: ESPAÇOS DE ATUAÇÃO A PARTIR DO SUS
}

\author{
Tânia Regina Krüger ${ }^{1}$
}

\section{RESUMO}

Na saúde o Serviço Social tem espaços próprios e tradicionais de atuação, mas com o SUS se abriu muitos espaços interdisciplinares e intersetoriais no âmbito da gestão, planejamento da política, controle social, educação e promoção da saúde nos quais o assistente social pode desenvolver ações não exclusivas da profissão. Assim, este texto procura refletir sobre as possibilidades e novos espaços de atuação que os princípios do SUS, o conceito ampliado de saúde e os determinantes sociais da saúde estão colocando para as várias profisssões, entre elas o Serviço Social. O pressuposto desta reflexão para identificar as potencialidades de atuação do assistente social na saúde está pautado nas semelhanças de fundamentos que possui o projeto ético-político da profissão com os princípios do SUS.

PALAVRAS-CHAVE: Serviço Social, Saúde, Prática Profissional.

\section{INTRODUÇÃO}

O presente texto procura refletir sobre alguns espaços de atuação que os princípios do SUS, o conceito ampliado de saúde e os determinantes sociais da saúde estão colocando para o Serviço Social. Entendemos que ao reconhecer à dimensão social da saúde, a política de saúde brasileira em muito alargou o espaço de atuação dos vários profissionais de saúde, entre eles o do assistente social. Nos últimos anos tem se evidenciado "a força que a temática do social e do trabalho com o social vem ganhando no âmbito da saúde, através das diferentes profissões" (MIOTO; NOGUEIRA, 2009, p.

\footnotetext{
${ }^{1}$ Assistente Social, mestre em Educação e Doutora em Serviço Social pela UFPE, Professora Adjunta do Departamento de Serviço Social da UFSC. E-mail: tania-re@,uol.com.br.
} 
223). Este alargamento das ações das outras profissões em direção ao social ao mesmo tempo em que pode enriquecer as potencialidades de práticas do assistente social colocam desafios no âmbito teórico, instrumental e político.

Na saúde o Serviço Social tem espaços próprios e tradicionais de atuação, mas com o SUS se abriu muitos espaços multidisciplinares, interdisciplinares e intersetoriais, também no âmbito da gestão e planejamento da política, nos quais o assistente social pode desenvolver ações não exclusivas da profissão. E é nestas novas relações que o espaço do social na saúde se torna um terreno comum a todas as áreas surgindo "profissionais que disputam papéis e tarefas com os assistentes sociais, pondo em xeque a legitimidade anteriormente conquistada [...]. É claro que os conflitos de atribuições aí localizáveis [...] não podem ser equacionados a base de regulações formais ou reivindicações corporativas [...], eles só podem ser enfrentados positivamente com novas competências sociopolíticas e teórico-instrumentais" (NETTO, 1996, p. 109).

É neste terreno em que os limites e fronteiras das ações dos profissionais de saúde não estão consensuados e não são lineares, que se pretende refletir sobre alguns espaços que o Serviço Social pode conquistar e mesmo requalificar atuações em setores tradicionais dos serviços de saúde. Este debate tem como pressuposto as semelhanças que os princípios do projeto ético-político da categoria têm com os fundamentos da Reforma Sanitária e os princípios do SUS.

Ao se procurar neste texto identificar as possibilidades colocadas para a prática do assistente social na saúde a partir do SUS, cabe indicar dois aspectos: aqui não se estará defendendo um especialista em Serviço Social na saúde e nem abandonando a perspectiva generalista da profissão. O que se pretende é apontar neste espaço sócio-ocupacional algumas particularidades e novas possibilidades de ações 
profissionais que estão colocadas para as profissões da saúde, entre elas o Serviço Social. Como segundo aspecto, indica-se mesmo que os fundamentos do projeto éticopolítico da profissão possuem semelhanças com os princípios do SUS, pensamos que a ação profissional não pode limitar seu horizonte a uma política, sob o risco de se subordinar a ações dos gestores das políticas públicas. Podemos afirmar que o SUS representa a maior e mais abrangente política social nestes 500 anos de história do Brasil, e por isto mesmo precisa ser fortalecido, mas as respostas profissionais que caminham na defesa do direito a saúde e o direito a vida, tem no SUS um aliado estratégico, assim como os demais direitos reconhecidos em 1988.

A organização deste texto está assim estruturada: inicialmente apresentamos algumas características da atuação do Serviço Social na saúde, seguida de indicações de como o Serviço Social da saúde participou da renovação profissional e da Reforma Sanitária. Seguindo algumas indicações de como nos anos 2000 a categoria profissional vem adensando seu debate na área. No segundo item propriamente apresentamos as reflexões das possibilidades de atuação do assistente social na saúde e as potencialidades contidas com a implementação do SUS em áreas de competências não exclusivas da profissão: planejamento e gestão, atenção via Estratégia Saúde da Família Núcleo de Apoio a Saúde da Família, espaços de participação social, ouvidorias, Política Nacional de Humanização, o debate sobre a Fundações Estatais de direito privado e a judicialização. 


\section{Considerações sobre o Serviço Social na Saúde e os vínculos com a Reforma}

\section{Sanitária}

Historicamente a saúde tem sido o maior empregador de assistentes sociais. Dos primórdios da profissão até o final dos anos de 1980, sua atuação neste campo se deu no âmbito curativo e por meio de abordagem individual. Até 1960 o Serviço Social não se apresentava com polêmicas internas significativas. A partir desta década alguns segmentos profissionais começaram a questionar a posição conservadora, articulados, sobretudo com a perceptiva de superação do subdesenvolvimento latino-americano, configurando assim o início do processo de reconceituação (BRAVO, 1996).

O período de renovação profissional no Brasil em meio a ditadura militar se desenvolveu em três direções: a perspectiva modernizadora, a reatualização do conservadorismo e a intenção de ruptura ${ }^{2}$. Não é intenção deste trabalho explicitar as tendências de cada uma destas vertentes, mas ressaltar que o Serviço Social na área da saúde no período de renovação esteve voltado predominantemente para a estratégia de modernização conservadora, com vinculação destacada na estrutura do complexo previdenciário de assistência médica. Nesta época o mercado de trabalho se ampliou em hospitais e ambulatórios e na previdência social, mas apenas na saúde individual e não na coletiva. A ação do Serviço Social na saúde continuou por todo período como sendo uma atuação psicossocial junto a pacientes e familiares. O surgimento do Movimento Sanitário não teve repercussões nos assistentes sociais vinculados a área. Do mesmo modo o processo organizativo e o aprofundamento teórico da profissão na direção da intenção da ruptura não influenciou o Serviço Social na saúde nem no nível do discurso, predominando a vertente modernizadora (BRAVO, 1996).

\footnotetext{
${ }^{2}$ Ver melhor caracterização de cada destas três perspectivas em NETTO, J. P. Ditadura e Serviço Social. $5^{\mathrm{a}}$ ed. São Paulo: Cortez, 2001. 
As tendências democráticas no país se avolumaram nos anos de 1980, impulsionando daí a vertente de intenção de ruptura dentro do Serviço Social. No entanto, os profissionais que trabalhavam na área da saúde parece que continuavam distantes das reflexões e na prática subalternos ao protagonismo médico, dominante na área. No final do período de redemocratização, os assistentes sociais começaram a participar timidamente de eventos, entre eles a $8^{\circ}$ Conferência Nacional de Saúde, os Congressos de Saúde Coletiva e apresentar trabalhos sobre saúde nos CBAS. Houve a preocupação com aprofundamento de temas como direitos, cidadania e políticas públicas.

O movimento de renovação do Serviço Social aconteceu em paralelo ao da saúde coletiva, com o Movimento de Reforma Sanitária, inclusive coincidindo em algumas categorias teóricas o debate: Estado, direitos sociais, prática institucional e políticas públicas. De outro modo, esta renovação tanto no Serviço Social quanto na saúde aconteceram em meio ao movimento de redemocratização da sociedade brasileira e de renovação das próprias Ciências Sociais, portanto, não se caracterizam como movimentos isolados.

A luta pela democratização da saúde, que ganhou corpo no Movimento pela Reforma Sanitária, está em íntima ligação com as mobilizações ocorridas no plano sociopolítico para a mudança da ordem autoritária para democrática. As soluções para os problemas de saúde do Brasil não se colocavam apenas como soluções técnicas, mas se afirmava que qualquer solução técnica é também política, e qualquer solução política passa pelo debate democrático. A opção pela radicalidade democrática identificava-se, entre os teóricos do sanitarismo, com o reconhecimento das determinações sociais do processo saúde e doença, com o reconhecimento da sociedade de classes e apresentação 
de propostas de transformação social. Estas perspectivas foram se perdendo com a institucionalização democrática dos anos de 1990 e 2000.

As determinações sociais do processo saúde e doença ficaram evidentes no conceito de saúde que permeou o debate da Reforma Sanitária e as proposições da $8^{\circ}$ Conferência. Este foi resumido por Sérgio Arouca (1987, p. 36):

Saúde não é simplesmente não estar doente, é mais: é um bemestar social, é o direito ao trabalho, a um salário condigno; é o direito a ter água, à vestimenta, à educação, e até, a informação sobre como se pode dominar o mundo e transformá-lo. É ter direito a um meio ambiente que não seja agressivo, mas que, pelo contrário, permita a existência de uma vida digna e decente; a um sistema, político que respeite a livre opinião, a livre possibilidade de organização e de autodeterminação de um povo. É não estar todo tempo submetido ao medo da violência, tanto daquela violência resultante da miséria, que é o roubo, o ataque, como a violência de um governo contra o seu próprio povo, para que sejam mantidos os interesses que não sejam os do povo.

Ainda que timidamente a Reforma Sanitária fosse portadora de um projeto societário, que esboçava uma proposta radicalmente democrática para o país e para a saúde. No entanto, ela não foi um processo homogêneo, mas recheado de contradições e por várias direções ídeo-políticas. Ainda que se tenham várias avaliações das conquistas políticas e jurídicas na saúde conseguidas com a Reforma Sanitária, também se avalia seus limites quanto a organicidade do Movimento com as bases sociais. Suas reivindicações centraram-se muito na formalização das conquistas, sendo relegadas às condições objetivas de efetivação dos direitos. Estes limites se evidenciam nestes 22 anos do SUS, quando os direitos permanecem reconhecidos na Carta Constitucional, 
mas na sua implementação observa-se suas dificuldades por meio do desfinanciamento, do sucateamento e dos programas verticalizados.

Como no Movimento Sanitário se reconhece no Serviço Social avanços no aspecto institucional, acadêmico e político. Uma das fontes inspiradoras e impulsionadoras do Movimento Sanitário foram os ideários progressistas que direta ou indiretamente estavam vinculados aos partidos de esquerda e a renovação crítica das Ciências Sociais. No decorrer do próprio Movimento e até o presente estes ideários carecem de uma rigorosa apreciação em termos de fundamentos, pois vejo, também como no Serviço Social, a influência de perspectivas marxistas a partir de fontes não originais e o seu processo político e intelectual foi se desenvolvendo de forma eclética ${ }^{3}$. As forças que reconheciam os fundamentos de classe da sociedade e do Estado conviveram com ideias reformistas e conciliadoras, vindos nas últimas décadas a sofrer forte influência das orientações teórico-metodológicas conservadoras.

Provavelmente potencializada pelo debate do projeto ético-político no final da década de 1990 e a primeira dos anos 2000 se verifica uma crescente participação dos assistentes sociais da saúde nas discussões da saúde coletiva. As publicações desta última década adensaram este debate sobre o Serviço Social na saúde, sobretudo no âmbito do SUS. Estão se tornando referências para o debate nacional as produções de Maria Inês Bravo, Ana Maria de Vasconcelos, Maurílio Matos, Maria Valéria Correia, Regina Célia Mioto, Vera Maria Nogueira, Dalva Horário, Jussara Mendes, entre outros. E mais recentemente o documento lançado pelo CFESS, construído partir de um debate nacional Os Parâmetros para atuação do Assistente Social na Saúde, vem

\footnotetext{
${ }^{3}$ Para compreender as influências marxistas de fontes indiretas no Serviço Social ver José Paulo Netto, Ditadura e Serviço Social. Na saúde vejo que a aproximação com os ideários marxistas e comunistas foram indiretos também, via ideias da revolução Cubana, Teologia da Libertação, Eurocomunismo e Reforma Sanitária Italiana. No entanto, esta afirmação carece de uma pesquisa rigorosa para efetivamente se conhecer estas fontes.
} 
explicitar as conexões entre o projeto ético-político da categoria com as bases da Reforma Sanitária e sugerir eixos para a prática do assistente social na saúde.

As linhas de pesquisa das pós-graduações em Serviço Social que tratam das políticas sociais estão contribuindo para adensar este debate do campo de saúde, tanto no âmbito da política de saúde propriamente (a tensão entre o projeto da Reforma Sanitária e o projeto privatista), como apontando novos espaços de atuação técnico e político (promoção de saúde e conselhos de saúde) e indicando possibilidades de requalificação das ações a partir das demandas tradicionais da saúde (atenção básica, plantões de hospitais, ações em equipes multiprofissionais). Outro indicador deste adensamento do debate e da atuação profissional neste espaço sócio-ocupacional tem sido a participação do Serviço Social nos programas de indução do Ministério da Saúde para formar profissionais com perfil para atuar no SUS entre eles as residências em área da saúde, as residências multiprofissionais em Saúde da Família, o Pró-Saúde e o PET Saúde.

\section{O SERVIÇO SOCIAL NA SAÚDE A PARTIR DO SUS}

Refletir sobre as possibilidades que o SUS coloca para a prática do assistente social supõe inicialmente um diálogo crítico com a herança intelectual e operacional da profissão na área da saúde e a identificação das tendências técnico-políticas colocadas pelos fundamentos da Reforma Sanitária e do SUS. Isto exige que o profissional esteja atento ao tempo histórico, superando visões ingênuas ou fatalistas da vida social, para decifrar as manifestações particulares no campo da saúde sobre as quais incidirá a ação profissional.

Tratar das ações profissionais no âmbito do SUS implica observar que na mesma medida em que esta política vem sendo defendida por inúmeros segmentos da 
sociedade brasileira por reconhecerem seu potencial enquanto política social inclusiva e universalizadora, por outro lado ela vem sendo despolitizada e banalizada em discursos que possuem também uma aparência de defesa. Assim, o Serviço Social ao pensar sua prática na saúde necessita compreender estas duas dimensões, fazendo leituras das demandas das instituições e dos usuários e identificar potenciais espaços de atuação, para evitar intervenções idealizadas, espontaneístas e restrita as relações interpessoais.

Um marco destas duas décadas do SUS tem sido o processo de municipalização o que consequentemente colocou os profissionais mais próximos dos usuários e dos processos de planejamento e gestão. Esta descentralização administrativa tem proporcionado uma crescente ampliação do mercado de trabalho para as profissões da área da saúde na esfera municipal, entre elas o Serviço Social.

Os princípios do $\mathrm{SUS}^{4}$, o conceito ampliado de saúde e o reconhecimento das determinações sociais do processo saúde e doença, que no espaço do executivo/gestão tem se materializado em vários programas, está demandando com frequência o trabalho do assistente social, não apenas como área exclusiva/ privativa. Ao mesmo tempo é por meio do reconhecimento das determinações sociais do processo saúde e doença e das necessidades de saúde que o assistente social tem construído novos espaços de atuação interdisciplinares, sobretudo nas áreas de promoção da saúde, educação em saúde e prevenção de doenças. Os referenciais clínicos que pautaram o atendimento tradicional, em parte cedem lugar aos referenciais das Ciências Sociais para a construção de

\footnotetext{
${ }^{4}$ I - universalidade de acesso em todos os níveis; II - integralidade de assistência em todos os níveis; III preservação da autonomia física e moral; IV - igualdade da assistência à saúde; V - direito à informação, às pessoas assistidas; VI - divulgação de informações dos serviços ao usuário; VII - utilização da epidemiologia para o estabelecimento de prioridades, a alocação de recursos e a orientação programática; VIII - participação da comunidade; IX - descentralização político-administrativa, com direção única em cada esfera de governo: a) descentralização para os municípios; b) regionalização e hierarquização da rede; X - integração das ações de saúde, meio ambiente e saneamento básico; XI - conjugação dos recursos financeiros, tecnológicos, materiais e humanos das três esferas na prestação de serviços; XII capacidade de resolução dos serviços em todos os níveis de assistência; XIII - organização dos serviços públicos de modo a evitar duplicidade de meios para fins idênticos (Brasil, 1990 - art, $7^{\circ}$ Lei 8.080/90).

Revista Serviço Social \& Saúde. UNICAMP Campinas, v. IX, n. 10, Dez. 2010
} 
perspectivas de trabalho que visam atender as demandas coletivas. É nesta perspectiva que possibilidades de trabalho multiprofissionais, interdisciplinares e intersetoriais estão contando com a presença de assistentes sociais, muitas vezes na sua coordenação, na gestão e no planejamento.

Em seguida passa-se a destacar novos desafios e espaços ocupacionais em áreas não exclusiva do Serviço Social na saúde a partir do SUS, sobretudo com o processo de municipalização. No setor de Planejamento o profissional pode desencadear planejamentos participativos com elaboração de diagnóstico e definição de prioridades em instâncias inframunicipais. Um planejamento participativo com os usuários e com os trabalhadores do sistema implica em socializar as informações da gestão sobre o andamento dos programas e serviços, os indicadores de serviços pactuados na Comissão Intergestora Bipartite - CIB, os indicadores epidemiológicos e fontes orçamentárias; implica também em retomar as proposições aprovadas nas Conferências de Saúde e envolver os Conselhos de Saúde Locais e Municipal no processo. Um planejamento participativo quadrienal, pressupõe continuidade e ampliação dos serviços, por isso seus sujeitos necessitam conhecer ao menos como foi a implementação do Plano Quadrienal do período anterior. Esta modalidade de planejamento participativo corre o risco de ter um direcionamento técnico dos trabalhadores que estão vinculados a gestão da mesma forma que o planejamento tradicional, mas a ênfase aqui é de que os profissionais a frente deste processo de planejamento o reconheçam também como momento de educação e de socialização da política, ainda que restrita aos serviços de saúde. A elaboração do Relatório Anual de Gestão da Saúde, como um momento de monitoramento e avaliação do Plano Quadrienal de maneira participativa, pode ser colocado entre as diretrizes contidas no próprio Plano. 
Apesar da forte tradição e legitimidade que o Serviço Social tem na área da saúde, as atuações no âmbito municipal e na atenção básica foram restritas, realidade esta que vem se alterando significativamente com municipalização proporcionada pelo SUS. Na medida em que os serviços públicos se aproximam das necessidades sociais e necessidades de saúde as demandas reprimidas se explicitam. Neste contexto o Serviço Social além de atuar no âmbito da gestão e do planejamento, tem ocupado espaços de coordenação na operacionalização de inúmeros programas de tratamento, de promoção e prevenção da saúde dirigidos a populações específicas (idade, gênero, patologias, dependente químicos, vigilância a saúde....). Iniciativas localizadas têm colocado o profissional na Estratégia Saúde da Família - ESF - e mais recentemente, a ampliação, com a regulamentação dos Núcleos de Apoio a Saúde da Família - NASFs. As possibilidades de ações de promoção da saúde com atuações multiprofisssionais, interdisciplinares e intersetoriais são amplas junto a ESF e o NASF. No caso, como exemplo, de ação intersetorial que vem se colocando como necessária é a relação com a área da Assistência Social via os CRAS; as condicionalidades do Programa Bolsa Família; os programas de atenção a população idosa, sobretudo os de proteção aos usuários vítimas de negligência e violência; os programas de tratamento dos dependentes químicos; os programas de apoio as mulheres vítimas de violência doméstica e a área de educação, especialmente a educação infantil pela falta de vagas em creches. No caso dos NASFs as ações de matriciamento, que parece estarem se reduzindo a discussão e ou repasse de casos complexos, pois na maioria das vezes as Equipes de Saúde da Família avaliam que já ultrapassaram sua competência, precisam também ser consideradas no âmbito das necessidades e dos determinantes da saúde local e da própria dinâmica da gestão dos serviços de saúde no âmbito municipal de regional. Para além da sobrecarga dos NASFs, tendo de ser referências entre 8 a 20 ESF, o 
planejamento da dinâmica enquanto equipe multiprofissional e a relação com as ESF numa perspectiva que se aproxima de um trabalho interdisciplinar é algo ainda que está em processo de construção. A organização política junto aos Conselhos Locais e as demais organizações comunitárias é algo a ser articulado nas ações da ESF e dos NASFs.

A área da Vigilância a Saúde que se operacionaliza via vários programas como a vigilância sanitária, epidemiológica, ambiental, saúde do trabalhador, doenças não transmissíveis - DANTs, alimentar e nutricional, de prevenção a violência e assistência farmacêutica, também é um campo da saúde historicamente bastante reduzido de atuação do assistente social. Trabalhar com vigilância a saúde na atualidade implica perceber que as doenças do perfil epidemiológico contemporâneo são previsíveis, mas não estão sendo devidamente prevenidas, que muitas doenças da modernidade são agravadas pela ausência de intervenções oportunas e precoces e que existem altos índices de mortes evitáveis e percentuais de exames diagnósticos, tratamentos medicamentosos e encaminhamentos desnecessários e de baixa qualidade, apesar dos conhecimentos e técnicas já disponíveis. A prática nestes espaços tem acontecido com o desenvolvimento de atribuições não exclusivas e os assistentes sociais têm assumido a coordenação destas vigilâncias ou mesmo de subprogramas como, por ex. na vigilância epidemiológica: da hanseníase, da tuberculose, das DSTs/AIDS, entre outros. É na área da vigilância a saúde que se pode perceber com grande nitidez as determinações sociais no processo saúde e doença. A atuação profissional atenta aos indicadores reais e os pactuados entre as três esferas de gestão e o perfil epidemiológico possibilita ações no âmbito da promoção da saúde, subsidia a elaboração dos subprogramas e as necessidades de capacitações dos trabalhadores da saúde. Mas pela tradição de ser um executor terminal de políticas sociais os assistentes 
sociais tem tido dificuldades de trabalhar com sistemas de informação e com indicadores epidemiológicos extraindo deles indicadores estratégicos e fazendo cruzamento de dados. Estes são instrumentos que subsidiam política e tecnicamente o profissional para sustentar seus argumentos, reconhecer os determinantes sociais da saúde, debater processos de planejamentos, articular trabalhos intersetoriais e mesmo apresentar de forma coletiva as demandas dos usuários.

A Atenção Básica e a Vigilância em Saúde com todo seu potencial de promoção, prevenção e de educação em saúde, bem como de educação política, podem possibilitar aos usuários acessarem a rede de serviços antes de adoecerem. Esta forma de atuação implica fazer também com que a atenção básica realmente funcione como a porta de entrada do SUS. Tensionar os nós críticos das dificuldades de acesso ao SUS está entre as competências técnico-políticas dos profissionais de saúde, no sentido de permitir que os usuários quando necessitem chegar aos serviços de média e alta complexidade tenham um diagnóstico precoce e em tempo de viabilizar tratamentos resolutivos e não apenas paliativos. A Atenção Básica e a Vigilância em Saúde são as ações que se utilizam pouco do chamado Complexo Industrial da Saúde, portanto, suas ações são contra-hegemônicas e se direcionam ao cumprimento do princípio universalizante do SUS.

Os espaços de debate político como os Conselhos e Conferências de Saúde que dão concretude a diretriz constitucional de participação da comunidade tem sido banalizados numa era que podemos denominar de conselhista. No entanto, apesar de não substituírem o papel dos movimentos sociais, estes possuem uma função importante na socialização e na educação política dos usuários e dos trabalhadores da saúde. Não defendemos aqui estes colegiados como um espaço de consenso, mas reconhecemos como plenárias que ao tensionar o debate também articulam forças sociais convergentes 
divulgam posições de defesa dos direitos, socializam informações sobre a burocracia da gestão, sobre financiamento, indicadores de saúde e doença e, sobretudo, apresentam as necessidades de saúde a partir da vocalização de seus usuários. Estudos têm evidenciado que estes espaços politico-organizativos não estão sendo ocupados na mesma medida em que o Serviço Social tem ampliado sua atuação na saúde ${ }^{5}$. Do mesmo modo evidenciam que a ação profissional não ocorre de forma sistemática e sim de acordo com as demandas apresentadas pelos gestores e conselheiros (NOSSWISTZ, 2008). A ação profissional dos assistentes sociais pode ser desempenhada em quatro condições, como: a) conselheiro; b) apoio técnico-administrativo, c) assessor e, d) observador e ou pesquisador. Ao se vincular aos Conselhos em qualquer uma destas posições o assistente social pode democratizar espaços e informações; problematizar e coletivizar demandas individuais; subsidiar os conselheiros nos processos de aprovação de planos, projetos e relatórios; realizar ações socioeducativas; articular pautas e demandas entre os demais Conselhos de direitos e políticas sociais; capacitar conselheiros e futuros conselheiros em articulação as entidades de usuários e trabalhadores; contribuir para divulgar agendas e decisões das plenárias; realizar pesquisas e viabilizar condições para que se tornem também um espaço de integração ensino e serviço na formação dos profissionais de saúde.

\footnotetext{
${ }^{5}$ Na pesquisa sobre o perfil dos assistentes sociais se contabilizou nos 24 CRESS e nas 3 Delegacias 61.151 profissionais inscritos. Nos resultados da pesquisa não há identificação do número de profissionais por área de atuação. Uma das indicações é que 30\% participam dos Conselhos de direitos ou políticas sociais. Destes 35,4 participam dos Conselhos de Assistência, 25,12\% da Criança e do Adolescente e $16,67 \%$ de Saúde (In. Pesquisa perfil profissional do assistente social no Brasil. CEFSS/CRESS/DSSUFAL, 2004). KRÜGER. T. R. e MARTINI, D. no texto Os egressos de Serviço Social da Residência Multiprofissional em Saúde da Familia da UFSC, 2010 (ainda não publicado), apontam que das sete assistentes sociais, ex-residentes em ESF da UFSC, apenas uma no ano de 2010 integra o Conselho Municipal de Assistência Social representando o gestor. Outra pesquisa de KRÜGER. T. R et al, 2010 (ainda não publicada), intitulada: $O$ periodo de vínculo formal dos alunos, perfil dos egressos $e$ ingressantes do Curso de Serviço Social da UFSC, evidencia que dos 36 egressos do curso de Serviço Social da UFSC entrevistados, 13 participam de algum Conselho de Política Social representando o gestor, 5 os trabalhadores e 1 os usuários.
} 
As ouvidorias que estão sendo utilizados pelos gestores como espaço de participação institucional ou de controle seus trabalhadores também estão se tornando campo de atuação do assistente social ainda que não propriamente vinculados aos mecanismos formais de participação social. No entanto, elas são um espaço contraditório, nos quais as suas demandas podem ser sistematizadas pelo assistente social no âmbito da instituição ou mesmo em pesquisas e serem publicizadas e colocadas na pauta dos Conselhos. Quando a pautadas nos Conselhos as respostas da instituição podem ser apreciadas e mesmo reorientadas.

Para apontar outros espaços de atuação no âmbito do debate político destacam-se aqui três temas que o Serviço Social precisa evitar debater e se inserir nas comissões de maneira ingênua: a Política Nacional de Humanização, o Projeto de transformar os serviços públicos em Fundações Estatais de direito privado e a judicialização da saúde. Estes três debates, que em si são temas para um texto em separado, priorizamos aqui apenas mencionar que são extremamente polêmicos e cheios de armadilhas, mas o Serviço Social não pode passar ao largo. A Política Nacional de Humanização - PNH - é uma resposta do Ministério da Saúde para as constantes e inúmeras denúncias de mau atendimento e filas desumanas. Entre as prioridades da PNH pode-se destacar: a redução das filas, a ampliação do acesso, o atendimento integral, acolhedor e resolutivo com base em critérios de risco, os usuários conhecerem os profissionais e a rede serviços de seu território, a educação permanente para os trabalhadores e a participação dos usuários e trabalhadores na gestão. Nesta quase uma década de PNH o que tem se visto é praticamente uma banalização da humanização, no sentido de que está sendo uma retórica repetida continuamente por gestores e alguns segmentos dos trabalhadores e mesmo da academia. Mas ouso afirmar que tem se transformado quase num discurso chavão e vazio de sentido, pois tem priorizado muito 
o assistencialismo, o voluntarismo e o atendimento de qualidade parece se reduzir à boa vontade do profissional. Isto porque entre as ações da PNH ao longo desta década não tem se observado medidas efetivas que tratem da infra-estrutura dos serviços de saúde, por exemplo, o aumento dos recursos e/ou a regulamentação de nova versão da Emenda Constitucional 29 de 2000, o sucateamento das instalações físicas e equipamentos das unidades e a não aprovação do Plano de Cargos, Carreira e Salários Único para os trabalhadores da saúde. Os assistentes normalmente estão entre os profissionais que coordenam ou integram as comissões de PNH nas instituições de saúde e por isto suas reflexões além de contemplar os aspectos subjetivos da humanização precisam indicar sua base material. A intenção humanizadora precisa de condições de infraestrutura física, técnica, administrativa e salarial para acontecer, sem desconsiderar ou reduzir a importância do que conhecemos como bom atendimento.

O projeto de transformar as instituições públicas em Fundações Estatais de direito privado já vem sendo rebatizado desde meados dos anos de 1990 com a proposta de contra reforma do Estado inicialmente patrocinada pelo governo FHC. No caso da saúde a proposta de transformar as instituições em Fundações se sustenta em objetivos de aumento da qualidade da gestão e racionalização do gasto público. Na mesma medida que a $\mathrm{PNH}$, o projeto das Fundações também ressalta a crise dos grandes hospitais, os problemas de gestão e do mau atendimento. Precisamos ficar atentos e como profissionais problematizar e politizar este tema no âmbito dos Conselhos, nos grupos com os usuários e com a gestão local, evidenciando que este projeto de contrarreforma do Estado em grande medida pretende transformar as políticas sociais que garantem os direitos dos trabalhadores em negócios que promoverão lucratividade para o capital. A nossa defesa é para que as várias dimensões da vida humana não se 
transformem em negócios em nome de uma pretensa eficiência e eficácia e nem que se indiferencie a natureza dos serviços públicos e privados. Segundo Granemam (2008):

[...] a forma é a fundação estatal, o conteúdo é a privatização dos serviços sociais, das políticas sociais, dos direitos dos trabalhadores. As fundações estatais são formas atualizadas das parcerias público-privadas, das Organizações da Sociedade Civil de Interesse Público (OSCIP), das Organizações Sociais (OS), das Fundações de Apoio e de numerosas outras tentativas que sempre tentam repetir o mesmo - privatizar - sob emblema diverso para que a resistência dos trabalhadores seja vencida. $\mathrm{O}$ essencial é que as reduções do Estado para o trabalho em nome da eficácia e da eficiência do serviço ao público, pela mesma medida, significam o aumento do Estado para o capital e é por isto que as denominamos privatização.

As políticas de contra reforma do Estado que reduziu e ampliou os critérios de elegibilidade em relação ao acesso aos direitos sociais desencadeou o fenômeno que temos reconhecido como judicialização. Ou seja, as pessoas ou instituições, não conseguindo acessar os serviços sociais via as instituições de políticas sociais recorrem a justiça. No caso brasileiro que não tivemos o Estado de Bem Estar Social, mas a Constituição de 1988 fez alguns acenos na sua direção facilitou com que também a judicialização se tornasse expressiva por aqui, especialmente nos anos 2000 . No caso da saúde, são os princípios do SUS quanto a acesso universal e a atenção integral que estão sustentando os processos judiciais por diferentes formas de tratamento no Brasil e no exterior, de medicamentos, alguns ainda nem reconhecidos pela ANVISA, equipamentos médico-hospitalares para uso domiciliar, o não reembolso ao SUS pelas operadoras de planos privados de saúde pelo atendimento prestado aos seus filiados e as isenções fiscais de serviços filantrópicos e privados de saúde. O que se questiona aqui não é o direito de todos a saúde, mas o fato de que a tradição das respostas judiciais Revista Serviço Social \& Saúde. UNICAMP Campinas, v. IX, n. 10, Dez. 2010 
serem individualizadas acabe por fragilizar o SUS enquanto um direito coletivo. Sabemos que o acesso a justiça na realidade brasileira é bastante elitizado e o que se tem observado é que são os segmentos sociais mais esclarecidos e em melhores condições socioeconômicas que protagonizam a judicialização da saúde ${ }^{6}$. O fornecimento de medicamentos por ação judicial tornou-se uma prática rotineira nos últimos anos e os números dessas demandas vêm aumentando consideravelmente os gastos com medicamentos pelas 3 esferas de governo, que por sua vez já vem se preocupando em construir uma forma de responder e analisar este fenômenos. Mas aqui vale considerar segundo dados do CEBES (2009) a principal demanda da judicialização ao contrário do que se pensa, o maior gasto não é com demanda individual por medicamento, mas é corporativa pela negociação de dívidas, por subsídios fiscais, correção de tabelas, o não ressarcimento do SUS e certificados de filantropia.

Os assistentes sociais como trabalhadores da saúde, ainda que não lidem diretamente com a prescrição ou dispensação dos medicamentos e procedimentos, recebem esta demanda pelos usuários. No imediato, muitas vezes orientamos os usuários a entrarem na fila da judicialização, mas o desafio é politizar o significado desta judicialização para que se não fragilize os fundamentos estruturantes do SUS, como serviço de acesso de direito coletivo. O debate sobre a judicialização deve contemplar o significado da explosão nos custos relacionados à incorporação destes medicamentos e tecnologias no sistema da saúde, as atividades de promoção da indústria farmacêutica e seu impacto na prescrição e dispensação racional dos medicamentos. Portanto as propostas devem considerar os critérios de acesso às tecnologias e medicamentos essenciais embasado no princípio da integralidade

\footnotetext{
${ }^{6}$ Para ilustrar ver reportagem: Ações por remédios caros favorecem ricos. Cotidiano. Folha de São Paulo. 24/07/2010. 
(CHIEFFI, BARATA, 2009). De outro lado nos cabe problematizar por que não tem judicialização para resolver problemas de falta de profissionais e sucateamento das unidades e equipamentos? Por que não conhecemos processos judiciais para incrementar as ações da atenção básica e a vigilância em saúde e nem processos que questionem que as atividades de promoção e prevenção estão subsumidas a assistência individual?

Nestes espaços de trabalho na saúde acima indicados um dos grandes potenciais tem sido as práticas interdisciplinares ${ }^{7}$. As experiências interdisciplinares têm colocado no âmbito do trabalho em saúde temas que historicamente foram negligenciados pelas práticas biomédicas, curativas e individuais: violência, dependência química, questões de gênero, sexual e etnia, poluição do meio ambiente, saneamento, movimentos sociais na área da saúde mental, de direitos reprodutivos, de portadores de patologia, controle social e participação social. Para tratar destes temas que fogem as tradicionais demandas e relações de trabalho médico-centradas, o assistente social, por sua formação com base nas Ciências Sociais e também se utilizando de indicadores socioeconômicos e epidemiológicos, pode ser um articulador deste debate, conseguindo indicar reflexões e formas de atendimento numa perspectiva de totalidade. Ou seja, pode pautar as reflexões no grupo de profissionais em direção ao reconhecimento das necessidades em saúde e das determinações sociais do processo saúde e doença, desvelando as leituras moralistas e higienistas que muitas vezes prevalecem nas discussões encaminhamentos dos grupos que pretendem atuar de

\footnotetext{
${ }^{7} \mathrm{O}$ trabalho interdisciplinar por si só não é uma crítica aos saberes específicos, mas na medida em que compreendemos que a nossa intervenção se dá numa realidade social, a interdisciplinaridade implica uma concepção de totalidade, que se traduz em conhecimentos somados e acumulados sobre os elementos históricos, culturais, políticos, princípios, valores, indicadores e determinantes socais de saúde e doença. Esta dinâmica de trabalho não significa coesão, consenso ou ausência de conflitos. Por isto um único profissional não pode ser visto como o único responsável pela desconstrução ou construção de uma prática interdisciplinar (KRÜGER, 2009).
} 
maneira interdisciplinar. A dimensão ético-política do projeto profissional tem enfatizado que cabe ao assistente social reconhecer as determinações sociohistóricas e econômico-políticas dos problemas que chegam na imediaticidade cotidiana dos serviços. Portanto, a capacidade analítica e de mediação do assistente social em problematizar as demandas imediatas explicitando suas conexões com uma demanda coletiva e indicando as conexões com as respostas das políticas sociais, pode qualificar este campo de debate do social que já tem sido reconhecido como comum aos demais trabalhadores da saúde.

\section{O SERVIÇO SOCIAL NA SAÚDE: AVANÇOS E DILEMAS EM DEBATE}

Debater a inserção do Serviço Social no campo da saúde, articulando a ação profissional às diretrizes do SUS, sinaliza para um estatuto diferenciado da profissão no campo da saúde, subsidia a ação do assistente social junto às equipes interdisciplinares, contribui para a materialização do projeto ético-político da categoria profissional no SUS e favorece um atendimento de qualidade à população usuária do sistema. Deste modo a inserção do Serviço Social na saúde, não pode ser circunscrita a uma política governamental, sujeita a modificações sazonais ou alterações políticas e programáticas. Portanto, é nesta perspectiva que as ações profissionais dos assistentes sociais podem ter maior centralidade e também escapar das referências conservadoras. Isto implica que estes profissionais recorram e se pautem no aparato teórico metodológico da profissão aliado aos conceitos fundamentais da área da saúde. Para uma atuação pautada na totalidade, é imprescindível que a ação profissional esteja sustentada no conhecimento da realidade dos serviços e necessidades dos sujeitos para as quais são destinadas, desdobrando-se na definição de projetos que contemplem tais necessidades. 
Os temas aqui apresentados enquanto potenciais espaços para a intervenção profissional que caminham na direção de fortalecer o projeto ético-político da profissão e os princípios do SUS não esgotam nossas possibilidades interventivas na área da saúde. E estas possibilidades se direcionam no caminho de superar intervenções que historicamente cumpriram um papel de aliviar as tensões, deixando satisfeito quem continua com dor, sem atendimento e sem medicação. Ou seja, realizar intervenções que sejam permeadas e orientadas pela noção de direito social, superando a prática do aconselhamento, da complacência e harmonização e do profissional reconhecido como o acolhedor, que organiza trabalhos em equipe e distribui tarefas.

Na prática cotidiana as requisições imediatas da fome, da dor, do sofrimento, da violência e da doença, as mediações com a universalidade estão submersas e veladas. O desocultamento das demandas cotidianas requer um procedimento cognitivo que não significa o abandono da empiria, mas a busca de suas leis universais. A prática do Serviço Social de acordo com esta perspectiva possibilita que a profissão ultrapasse os limites da subalternidade histórica e permite outras formas de legitimidade profissional, que não àquela dada apenas pelo empregador e gestores de serviços públicos. E nesse caso temos o grande desafio de trabalhar na direção entre o SUS legal e o SUS real.

\begin{abstract}
In health, social service has its own and traditional spaces of performance but with SUS many interdisciplinary and intersecting spaces were open in the scope of management, politics planning, social control, education and health promotion which are areas where the social worker can develop actions that are not exclusive to their profession. Thus, this text intends to reflect on the possibilities of new acting spaces that the SUS principles, the extended concept of health and the social determiners of health are placing to several professions, among them the social service. The presupposition of this reflection is to identify the performance potentialities of the social worker in health is
\end{abstract}


based on similarities of the principles that the profession's ethical-political project has with the principles of SUS.

KEYWORDS: Social Work, Health, Professional Practice

\section{REFERÊNCIAS BIBLIOGRÁFICAS}

BRAVO, M.I. Serviço Social e Reforma Sanitária: lutas sociais e práticas profissionais. São Paulo: Cortez. Rio de Janeiro: Ed UERJ, 1996.

BRAVO, M.I.S.; MATOS, M.C. Reforma Sanitária e Projeto Ético-Político do Serviço Social: elementos para o debate. In: BRAVO, M.I.S. et al. Saúde e Serviço Social. $2^{\mathrm{a}}$. Ed. São Paulo: Cortez, 2006a.

CEBES. Nova diretoria da ANS é contestada. Blog. 13/10/2009. http://www.cebes.org.br:80/default.asp?site_Acao=mostraPagina\&paginaId=167\&acao $=\underline{=}$ ibe $\& \mathrm{bID}=163$

CHIEFFI, A.L. e BARATA. R.B. Judicialização da política pública de assistência farmacêutica e equidade. In: Caderno de Saúde Pública. vol. 25, no. 8. Rio de Janeiro. Aug. 2009.

GRANEMANN, S. Fundações Estatais: Projeto de Estado do Capital Rio de Janeiro. 2008. In. http://www.fasubra.org.br/siteAsp/download/CED-0005.pdf. Acessado em 23/08/2009.

KRUGER, T.R. O projeto ético-político nos trabalhos do Serviço Social da saúde: um debate a meio caminho, Fpolis, 08/2006. Artigo apresentado no concurso para professor adjunto ao DSS/UFSC.

MIOTO, R.C.T; NOGUEIRA, V. M. R. Serviço Social e Saúde - desafios intelectuais e operativos. SER Social, Brasília, v. 11, n. 25, p. 221-243, jul./dez. 2009. 
NETTO, J. P. Transformações societárias e Serviço Social - notas para uma análise prospectiva da profissão no Brasil. In: Serviço Social \& Sociedade. São Paulo: Cortez, 1996, n. 50, p. 87-132.

NOSSSWITZ. J. A ação profissional do assistente social nos Conselhos Municipais de políticas públicas. Dissertação de Mestrado. Florianópolis. PPGSS/CSE/UFSC, 2008.

PEREIRA, J.R. Análise das demandas judiciais solicitando medicamentos encaminhados à diretoria de assistência farmacêutica da Secretaria de Estado da Saúde de Santa Catarina nos anos de 2003 e 2004. Florianópolis, UFSC, 2006. 132 p. VASCONCELOS, A.M. A prática do Serviço Social: cotidiano, formação e alternativas na área da saúde. $3^{\text {a }}$ ed. São Paulo: Cortez, 2006. 